\title{
A TRILOGIA CELULAR-TORRE-ANTENA COMO UMA EXPRESSAOO DA TERRITORIALIDADE INFORMACIONAL NO BRASIL
}

\author{
Marília Steinberger
}

p. $73-97$

Como citar este ar tigo:

STEINBERGER, M., Alexandre Resende Tofeti. The Cellphone -TowerAntenna Trilogy As An Expression Of Informational Terrioriality In Brazil.

Revista Eletrônica: Tempo - Técnica - Território, v.6, n.1 (2015), p.

73:97 ISSN: 2177-4366. DOI: https://doi.org/10.26512/ciga.v6i1.20913

Disponível em: http://periodicos.unb.br/index.php/ciga/

Este obra está licenciado com uma Licença Creative Commons

Atribuição-NãoComercial 4.0 Internacional. 
74 www.ciga.unb.br

Steinberger, $\mathrm{M}$.

\title{
A TRILOGIA CELULAR-TORRE-ANTENA COMO UMA EXPRESSÃO DA TERRITORIALIDADE INFORMACIONAL NO BRASIL
}

\author{
Marília Steinberger \\ Economista, Doutora em Planejamento Urbano e Regional pela Universidade de São Paulo, \\ professora do Departamento de Geografia da Universidade de Brasília e pesquisadora \\ CNPq/Núcleo de Estudos Urbanos e Regionais - NEUR \\ $\underline{\text { rtlia@solar.com.br }}$
}

\begin{abstract}
Alexandre Resende Tofeti
Geógrafo, Mestre em Geografia pela Universidade de Brasília, Doutorando pelo Departamento de Geografia da Universidade de Brasília.

tofeti@unb.br

\section{A trilogia celular-torre-antena como uma expressão da territorialidade informacional no Brasil (Resumo)}

A partir dos anos 2000 observa-se na paisagem dos principais centros urbanos mundiais a multiplicação de torres e antenas de telefonia celular. Embora em décadas anteriores já houvesse torres de rádio e de telefone fixo, elas não eram constantes. Tal constância é uma peculiaridade do período técnico-científico-informacional. O sistema de telefonia celular é composto por uma trilogia de objetos geográficos inseparáveis: celular, torre e antena. O propósito do artigo é analisar a territorialidade dos objetos desta trilogia que se expressa por meio da sua distribuição espacial e da ação de agentes sociais envolvidos na localização e regulação no Brasil. Á luz de um referencial teórico e empírico, a principal contribuição oferecida é reconhecer a existência de uma territorialidade informacional.

Palavras-chave: Celular, torre, antena, territorialidade.

The cellphone-tower-antenna trilogy as an expression of informational territoriality in Brazil (Abstract)

From the 2000s on it is observed in the landscape of the main urban centers worldwide the multiplication of cellphone's towers and antennas. Although in the previous decades, towers of radio and landlines could already be found, they were not constants. Such constancy, is part of the technical-scientific-informational period. The cellphone system is composed by a trilogy of inseparable geographic objects: cellphone, tower and antenna. The purpose of the paper is to 
analyze the territoriality of these trilogy objects, which expresses itself through its spatial distribution and the action of social agents involved in the location and regulation in Brazil. Based on a theoretical and empirical framework, the main contribution offered is to recognize the existence of a informational territoriality.

Keywords: Cellphone, tower, antenna, territoriality.

\section{La trilogie téléphone portable-tour-antenne comme une expression de la territorialité informationnelle au Brésil (Resumé)}

Depuis le début des années 2000, on observe la multiplication des tours et antennes de téléphones portables dans les centres urbains du monde entier. Certes, dans les années précédentes, on voyait déjà des tours de radios et de lignes de téléphone, mais elles n'étaient pas aussi omniprésentes. Un tel développement fait partie de l'ère technologico-scientificoinformationnelle. Le système de téléphonie mobile induit une trilogie inséparable d'objets géographiques: téléphone portable, tour et antenne-relais. L'objectif de l'article est d'analyser la territorialité de ces objets, qui s'exprime à travers la distribution spatiale et l'action des acteurs sociaux impliqués dans la localisation et la réglementation au Brésil. A l'aide d'une étude théorique et empirique, la principale contribution cherche à reconnaître l'existence d'une territorialité informationnelle.

Mots clés: téléphone portable, tour, antenne, territorialité

\section{Introdução}

$\mathrm{Na}$ maioria dos centros urbanos mundiais é visível, desde o início dos anos 2000, a presença de torres e antenas de telefonia celular. Em décadas anteriores já havia torres e antenas de rádio e de telefone fixo, mas elas não eram objetos geográficos constantes na paisage $\mathrm{m}$. Tal constância é um dos símbolos do período técnico-científico-informacional que, para Milton Santos, corresponde à 'cientifização e tecnicização da paisagem', ideia básica para se discutir territorialidade informacional.

O celular, denominação genérica que inclui aparelhos convencionais, smartphones e modens portáteis, foi criado para facilitar a conversação telefônica entre duas pessoas sem o apoio de um ponto fixo. Com a evolução das Tecnologias de Informação (TI), acumula várias funções além da conversação telefônica, a exemplo da internet, da câmara fotográfica e dos 
jogos eletrônicos. Essa multifuncionalidade faz com que o celular seja um objeto geográfico de troca e de acesso a informações de amplo espectro.

No Brasil, o ano de 2004 é considerado pelos especialistas como o primeiro marco da telefonia celular porque houve uma inversão no sistema de telecomunicações - o número de linhas telefônicas móveis suplantou as fixas. Dadas as controvérsias, ocorridas no biênio 2010/2011, sobre a distinção entre acessos e aparelhos celulares, o ano de 2012 é aceito como o segundo marco, pois conforme a Agência Nacional de Telecomunicações (Anatel), o numero de aparelhos ultrapassou a população ao alcançar a teledensidade de 132 celulares para cada 100 habitantes, o que atesta a sua popularização.

Para acolher essa crescente demanda foi necessário instalar uma grande quantidade de torres e antenas nos centros urbanos que concentravam mais usuários. Daí veio a percepção empírica sobre a inseparabilidade entre celular, torre e antena, objetos geográficos componentes de uma trilogia que configura um sistema e expressa uma territorialidade informacional. Assim, cabe indagar: como se expressa a territorialidade informacional da trilogia celular-torre-antena no Brasil?

O presente artigo visa responder a esta pergunta com uma discussão realizada em três seções. Inicialmente, expõe-se a história do sistema de telefonia celular à luz de um referencial teórico que aciona as noções de tecnosfera, espaço-tempo, ciberespaço, território usado e territorialidade a fim de se chegar ao entendimento de territorialidade informacional. Em seguida, utilizando dados de 2012, analisa-se a distribuição espacial dos objetos geográficos da trilogia celular-torre-antena. Primeiramente, com base no número de celulares e na população residente das unidades federativas brasileiras. Posteriormente, com base no número de torres/antenas (terminologia da Anatel) instaladas nos centros urbanos hierarquicamente mais importantes definidos pelo Instituto Brasileiro de Geografia e Estatística no estudo das "Regiões de Influência das Cidades" (IBGE-Regic). Ambas as análises permitem classificar as unidades federativas e os centros urbanos de acordo com a sua maior ou menor carga informacional. Por último, discute-se a ação dos agentes sociais envolvidos na localização e na regulação dos objetos geográficos da trilogia celular-torre-antena que, juntamente com a sua distribuição espacial, constituem duas formas de expressão da territorialidade informacional no Brasil.

\section{1 - O sistema de telefonia celular no contexto do período técnico-científico- informacional}


A telefonia móvel do princípio do século XXI representa um avanço em relação à segunda metade do século XX. O embrião surgiu nos EUA, na cidade de St. Louis/Missouri, mais precisamente em 1946, quando os primeiros aparelhos foram instalados em veículos. No entanto, os custos elevados e a precária qualidade restringiram o serviço a poucas pessoas (DODD, 2001).

Esses aparelhos já adotavam a estrutura de uma estação base, depois chamada de 'estação rádiobase', composta por uma torre que dava suporte para uma antena emitir sinal ao telefone móvel (STALLING, 2002). Tal estrutura vem sendo mantida desde a concepção dos protótipos desenvolvidos nos anos 1960 e 1970, com o diferencial de que se utiliza maior quantidade de torres e antenas a fim de aumentar a capacidade de transmissão, reduzir as freqüentes interrupções e ampliar o número de clientes. A palavra celular deriva da repartição da área de influência das torres e antenas em subáreas, denominadas células, razão por que se passou a usar o termo 'telefonia celular'.

Nas décadas de 1980 e 1990, a miniaturização dos microprocessadores trouxe inovações no próprio aparelho que, não só diminuiu de tamanho como teve seus circuitos internos substituídos por transistores, proporcionando um salto na prestação de serviços da primeira para segunda geração de telefonia celular.

A partir dos anos 2000, com a popularização do celular e a convergência tecnológica, cada vez mais células são demandadas para receber um crescente volume de tráfego de voz e de dados, o que deu origem à terceira (3G) e a quarta geração (4G) de telefonia celular. Os serviços 4G atendem um raio quatro vezes menor comparado aos 3G, motivo pelo qual requerem mais estações rádiobase, o que significa uma nova multiplicação de torres e antenas.

Diante dessa breve história, confirma-se que a telefonia celular é composta por três objetos geográficos inseparáveis: celular, torre e antena. Não há como falar sobre celular sem falar em torre e antena. Daí admitir-se que compõem uma trilogia. No dizer de Milton Santos há "uma verdadeira tecnosfera, uma natureza crescentemente artificializada, marcada pela presença de grandes objetos geográficos, idealizados e construídos pelo homem, articulados entre si em sistemas." (SANTOS, 1996, p. 127). A tecnosfera, de acordo com Santos, é um dos elementos do espaço:

[...] o espaço pode ser entrevisto através da tecnosfera e da psicosfera que, juntas, formam o meio técnico-científico. A tecnosfera é o resultado da crescente artificialização do meio ambiente. A esfera natural é crescentemente substituída por uma esfera técnica, na cidade e no campo. A psicosfera é o resultado das crenças, desejos, vontades e hábitos que inspiram comportamentos filosóficos e práticos, as relações interpessoais e a comunhão com o Universo. (SANTOS, 1996, p. 32) 
A trilogia celular-torre-antena é emblemática do meio técnico-científico porque seus objetos geográficos, articulados em sistema, fazem parte da tecnosfera. Logo, cabe reconhecer que há um 'sistema de telefonia celular'. Simultaneamente, a trilogia faz parte da psicosfera, porque o celular tornou-se um objeto de desejo.

O meio técnico-científico considerado por Santos como balizador do período atual da história do meio geográfico, precedido pelo meio natural e pelo meio técnico, depois foi por ele chamado de 'meio técnico-científico-informacional'. Diferencia-se dos anteriores não só pela interação entre técnica e ciência, mas pela carga informacional. Para o autor "neste período, os objetos técnicos tendem a ser ao mesmo tempo técnicos e informacionais [...] na verdade, a energia principal de seu funcionamento é também a informação". (SANTOS, 2002, p. 238)

Daí o pressuposto de que o celular, a torre e a antena, dada sua carga informacional, além de objetos geográficos, são 'objetos técnico-informacionais'. São ícones da essência do meio técnico-científico-Informacional que assume duas características marcantes: a produção tecnológica acumulada em diferentes tempos históricos e o crescimento exponencial da circulação de informações.

Sobre a primeira característica, David Harvey argumenta que as periódicas crises de superprodução, geradas no âmbito do sistema capitalista, começaram a ser superadas com o encurtamento do tempo e com o ganho de eficiência na distribuição espacial das mercadorias. Ambos resultam do que o autor denomina de 'compressão espaço-tempo' (HARVEY, 1993, p. 219). Na mesma direção, Paul Virilio refere-se ao "declínio do primado da extensão do espaço geográfico em prol da ausência de duração do tempo cronográfico" (VIRILIO, 1993, p. 95).

Levando em conta a noção de espaço-tempo, vírgula supõe-se que o celular esteja contribuindo para promover não só o encurtamento e a ausência da duração do tempo, mas o declínio da extensão do espaço e a sua conseqüente dilatação. Tal dilatação só é possível, segundo Virilio, por que:

Daqui em diante, os seres e as coisas que nos cercam não são nada mais do que CAMPOS, e o real, uma REDE única, mas uma rede CIBERNÉTICA, já que tudo é interior ao 'campo' e somente a ele. [...] O CIBERESPAÇO ou, mais exatamente, 'o espaço-tempo cibernético', surgirá dessa constatação. (VIRILIO, 1993, p. 113 e 122)

O ciberespaço de Virilio, traduzido como espaço-tempo cibernético, enseja trazer aqui definições como a de Pierre Lévy, para quem o ciberespaço é o novo meio de comunicação que nasce com a interconexão mundial dos computadores. Envolve "não apenas a 
infraestrutura material da comunicação digital, mas também o universo oceânico de informações que ela abriga, assim como os seres humanos que navegam e alimentam esse universo". (LÉVY, 1999, p. 17). De fato, o celular, hoje fundido com o computador, cada vez mais se insere no ciberespaço de Lévy. Por ser dotado de praticidade e versatilidade, provoca a intensiva utilização do sistema de infraestrutura digital e o acesso ao universo de informações das redes.

No contexto do meio técnico-científico-informacional, da compressão espaço-tempo e do ciberespaço, aparecem os debates sobre desterritorialização. Rogério Haesbaert questiona a desterritorialização ao afirmar: "ignora-se que mesmo o espaço 'virtual' do ciberespaço não pode prescindir de bases materiais e contatos face-a-face." (HAESBAERT, 2006, p. 59)

O sistema de telefonia celular é um dos mais representativos exemplos dessa afirmação, pois os portadores de celular não têm necessariamente nem território de origem nem destino fixos e, portanto, têm possibilidade de acessar e gerar fluxos de comunicação entre vários territórios. Contudo, precisam das torres e antenas que constituem as suas bases materiais.

Para Boaventura Souza Santos, essas bases materiais equivalem a uma imprescindível 'âncora territorial' (SOUZA SANTOS, 2001) mesmo em tempos de globalização. No caso do sistema de telefonia celular, as torres e as antenas são as âncoras que possibilitam o crescimento exponencial da circulação de informações, a segunda característica marcante do meio técnico-científico-informacional.

Nesse sentido, Santos explica que os objetos precisam ser "localizados de forma adequada" de modo a produzir "os resultados que deles se esperam". Complementarmente, reconhece a "cientifização e tecnicização da paisagem" (SANTOS, 2002, p. 215) que, na trilogia ora discutida, refere-se à multiplicação de torres e antenas, objetos cuja localização é decidida pelas ações dos agentes sociais.

Objetos e ações estão contidos na acepção de espaço enquanto "união indissolúvel de sistemas de objetos e sistemas de ações que nos indicam como o território é usado: como, onde, por quem, por quê, para quê" (SANTOS \& SILVEIRA 2001, p. 11). A categoria 'território usado' permite introduzir a noção de territorialidade que deriva da compreensão de território como uma 'extensão apropriada e usada'. Quer dizer, a territorialidade não está propriamente no território, mas no uso do território.

Alguns autores tem se preocupado em esclarecer o significado de territorialidade. Marcelo José Lopes de Souza defende a ideia de que a territorialidade está ligada a "relações 
de poder espacialmente delimitadas" (SOUZA, 1995, p. 99). Neio Campos e Mara Flora Krahl sugerem que a territorialidade está vinculada às práticas capazes de assegurar "a apropriação e a permanência de um dado território por um determinado agente social" (CAMPOS \& KRAHL, 2006, p. 97). Robert Sack diz que territorialidade é "a tentativa, por indivíduo ou grupo, de afetar, influenciar ou controlar pessoas, fenômenos e relações ao delimitar e assegurar seu controle sobre certa área geográfica" (SACK, 1986, p. 21). (fechar aspas)

Esses significados, longe de se contradizerem, são complementares. A palavra-chave de Souza é poder, a de Campos \& Krahl é agente social e a de Sack é controle. Acrescentando a essas palavras o binômio espaço-território usado de Santos \& Silveira, propõe-se que territorialidade seja entendida como: poder exercido por agentes sociais que produzem espaço, por meio de objetos e ações, para obter o controle sobre o uso de um determinado território.

No sistema de telefonia celular, a territorialidade é exercida pelo poder dos agentes sociais que obtêm o controle sobre o uso de determinados territórios ao decidir sobre a localização e a regulação dos objetos técnico-informacionais da trilogia celular-torre-antena. No entanto, mais do que uma territorialidade, trata-se de uma 'territorialidade informacional' que se expressa na distribuição espacial desses objetos e na ação de agentes sociais, conforme discutido a seguir.

\section{2 - A territorialidade informacional expressa na distribuição espacial da trilogia celular-torre-antena}

O sistema de telefonia celular brasileiro começou a ser implantado nos anos 1980 na cidade do Rio de Janeiro, precursora da telefonia fixa no final do século XIX. Foi dimensionado com uma capacidade para atender 10 mil consumidores, mas a maioria não teve acesso ao serviço por ser muito dispendioso - cada aparelho custava cerca de 20 mil dólares. A disseminação do celular só ocorreu no princípio da década de 1990, com a melhoria da infraestrutura de telecomunicações e, logo depois, em 1997, com a abertura do mercado para a iniciativa privada que reduziu seu preço.

Em 2012, para uma população de quase 200 milhões existiam 256 milhões de celulares comercializados pelas quatro operadoras principais que detinham as seguintes fatias do mercado: Vivo - 29,5\%; TIM - 26,8\%; Claro - 24,6\%; e Oi - 18,6\%. Esses números são o resultado da competitividade fomentada por uma estratégia de popularização que abrange dois planos alternativos: pós-pago - assinatura mensal; e pré-pago - compra antecipada de créditos. O último é o escolhido por $80 \%$ dos consumidores por controlar os gastos sem 
comprometer a renda. Porém, para que as operadoras proporcionem um serviço de excelência é preciso uma quantidade de torres/antenas adequadamente distribuídas no território.

A análise da distribuição espacial dos objetos técnico-informacionais da trilogia celulartorre-antena, baseada na população residente, no número de celulares e de torres/antenas, será realizada por meio de dois indicadores que medem a carga informacional por macrorregião:

- teledensidade - retrata a demanda per capita nas unidades federativas (relação entre o número de celulares e a população residente); e

- habitantes por torre/antena - retrata a oferta de infraestrutura implantada nos centros urbanos hierarquicamente mais importantes (relação entre população residente e o número de torres/antenas).

Sobre a teledensidade, apresentada no Quadro 1, verifica-se que oito unidades federativas detêm aproximadamente dois terços da população e do número de celulares - São Paulo, Minas Gerais, Rio de Janeiro, Bahia, Rio Grande do Sul, Paraná, Pernambuco e Ceará. Verifica-se também que, em praticamente todas as unidades federativas, a teledensidade está acima de 1,00, ou seja, o número de celulares ultrapassa a população.

Entretanto, as unidades federativas que possuem mais população e mais celulares não necessariamente têm as maiores teledensidades. Ao lado de São Paulo, Rio de Janeiro e Rio Grande do Sul, estão o Distrito Federal, Mato Grosso do Sul, Rondônia, Goiás, Mato Grosso e Rio Grande do Norte, cujas teledensidades são mais elevadas do que a média brasileira de 1,32. Adotando tal média como parâmetro, essas nove unidades federativas são as que possuem as maiores cargas informacionais segundo a teledensidade, conforme a Figura 1. Chama atenção o fato de todas as unidades federativas do Centro-Oeste terem alta carga informacional, o que provavelmente está associado à sua inserção na fronteira econômica do país, onde predomina a agroindústria de alta tecnologia. Em oposição, apenas uma unidade federativa do Nordeste, o Rio Grande do Norte, aparece com teledensidade maior que a média. 


\begin{tabular}{|c|c|c|c|c|}
\hline \multicolumn{5}{|c|}{ Quadro 1: Carga Informacional das Unidades Federativas segundo a Teledensidade } \\
\hline Macrorregião & Unidade Federativa & $\begin{array}{c}\mathbf{N}^{\circ} \text { de } \\
\text { celulares }^{1}\end{array}$ & População ${ }^{2}$ & Teledensidade \\
\hline \multirow{7}{*}{ Norte } & Acre-AC & 912.041 & 758.786 & 1,20 \\
\hline & Amapá-AP & 910.746 & 698.602 & 1,30 \\
\hline & Amazonas-AM & 3.995 .972 & 3.590 .985 & 1,11 \\
\hline & Pará-PA & 8.473 .554 & 7.792 .561 & 1,09 \\
\hline & Rondônia-RO & 2.234 .709 & 1.590 .011 & 1,41 \\
\hline & Roraima-RR & 499.229 & 469.524 & 1,06 \\
\hline & Tocantins-TO & 1.773 .686 & 1.417 .694 & 1,25 \\
\hline \multirow{9}{*}{ Nordeste } & Alagoas-AL & 3.585 .259 & 3.165 .472 & 1,13 \\
\hline & Bahia-BA & 16.831 .908 & 14.175 .341 & 1,19 \\
\hline & Ceará-CE & 9.980 .529 & 8.606 .005 & 1,16 \\
\hline & Maranhão-MA & 5.733 .335 & 6.714 .314 & 0,85 \\
\hline & \begin{tabular}{|l|} 
Paraíba-PB \\
\end{tabular} & 4.564 .087 & 3.815 .171 & 1,20 \\
\hline & Pernambuco-PE & 11.529 .224 & 8.931 .028 & 1,29 \\
\hline & Piauí-PI & 3.588 .338 & 3.160 .748 & 1,14 \\
\hline & Rio Grande do Norte-RN & 4.296 .349 & 3.228 .198 & 1,33 \\
\hline & Sergipe-SE & 2.631 .708 & 2.110 .867 & 1,25 \\
\hline \multirow{4}{*}{ Centro-Oeste } & Distrito Federal-DF & 5.979 .700 & 2.648 .532 & 2,26 \\
\hline & Goiás-GO & 8.704 .742 & 6.154 .996 & 1,41 \\
\hline & Mato Grosso-MT & 4.324 .388 & 3.115 .336 & 1,39 \\
\hline & Mato Grosso do Sul-MS & 3.625 .863 & 2.505 .088 & 1,45 \\
\hline \multirow{4}{*}{ Sudeste } & Espírito Santo-ES & 4.538 .319 & 3.578 .067 & 1,27 \\
\hline & Minas Gerais-MG & 24.865 .808 & 19.855 .332 & 1,25 \\
\hline & Rio de Janeiro-RJ & 22.718 .715 & 16.231 .365 & 1,40 \\
\hline & São Paulo-SP & 62.947 .829 & 41.901 .219 & 1,50 \\
\hline \multirow{3}{*}{ Sul } & Paraná-PR & 13.878 .006 & 10.577 .755 & 1,31 \\
\hline & Rio Grande do Sul-RS & 14.883 .611 & 10.770 .603 & 1,38 \\
\hline & Santa Catarina-SC & 8.123 .412 & 6.383 .286 & 1,27 \\
\hline \multicolumn{2}{|c|}{ Total Brasil / Média } & 256.131 .067 & 193.946 .886 & 1,32 \\
\hline
\end{tabular}

Fontes: 1 -Anatel, 2012 (a); 2-IBGE, Estimativa da População, 2012 


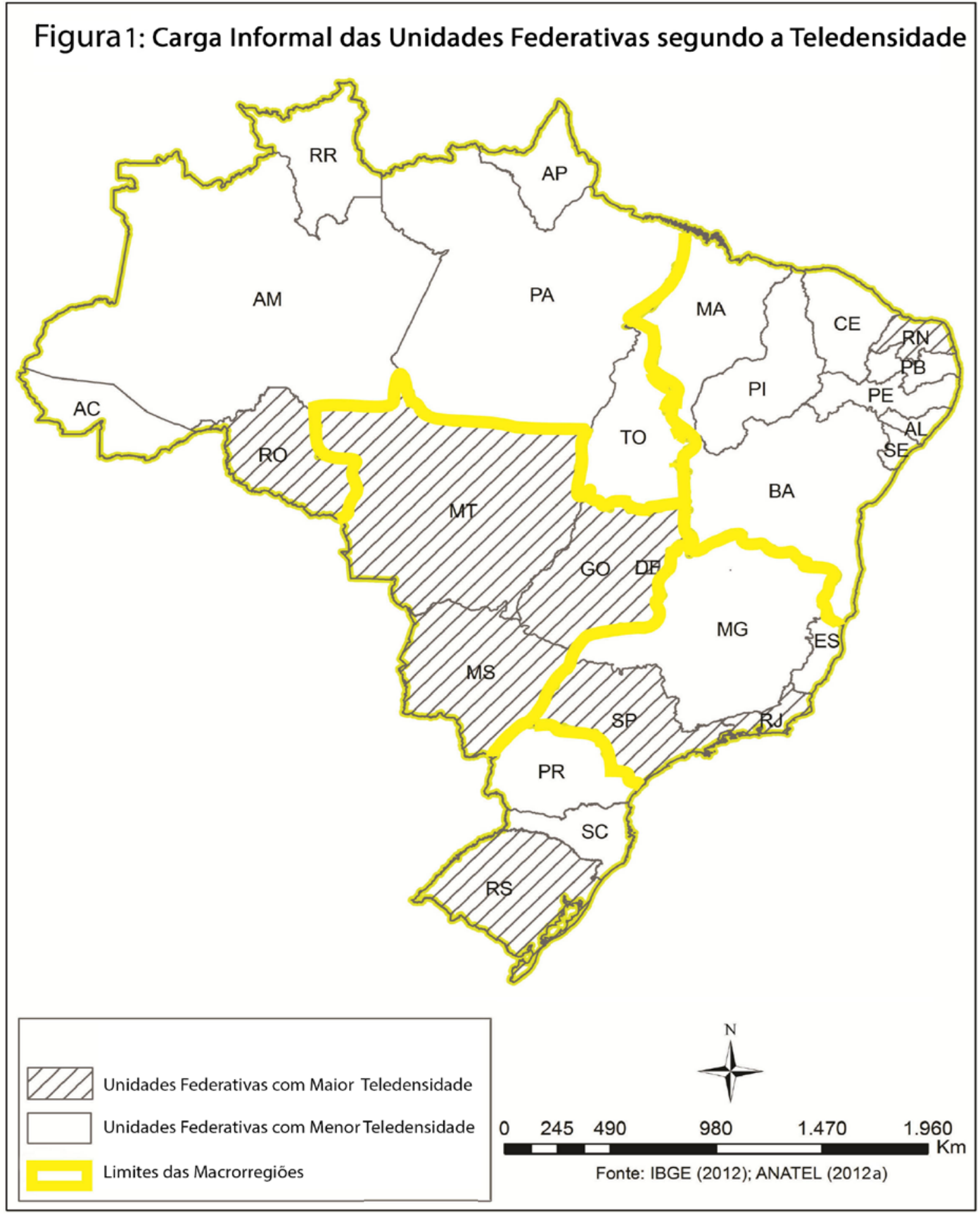

Ainda quanto à teledensidade das unidades federativas, vale destacar dois casos extremos: o Maranhão e o Distrito Federal. O primeiro tem a menor teledensidade do país $(0,85)$, enquanto o Distrito Federal, que abriga somente Brasília, é uma das unidades

Revista Eletrônica: Tempo - Técnica - Território, V.6, N.1 (2015), 73:97 ISSN: 2177-4366 
federativas com menor população, mas sua teledensidade é a maior do Brasil $(2,26)$, ou seja, possui mais de dois celulares por habitante. Esses dados são condizentes com o Produto Interno Bruto (PIB) per capita do Maranhão $(\mathrm{R} \$ 7.859,71)$ e do Distrito Federal $(\mathrm{R} \$ 63.020,02)$ (IBGE, 2011).

A teledensidade, que mede a carga informacional contida na demanda agregada de celulares por unidade federativa, deve ser complementada por outro indicador que mede a carga informacional contida na oferta de infraestrutura implantada para atender a demanda: habitantes por torre/antena nos centros urbanos mais importantes de cada unidade federativa. Tal indicador representa a âncora territorial da trilogia e refina a teledensidade, na medida em que não trata o território das unidades federativas como se fosse homogêneo.

Para tanto, utiliza-se como referência o mencionado IBGE-Regic que divide os centros urbanos brasileiros nos seguintes grupos: Grande Metrópole Nacional, Metrópole Nacional, Metrópole, Capital Regional A, B e C, Centro Sub-Regional e Centro de Zona. Na presente discussão, selecionaram-se os seis primeiros que perfazem 82 centros sendo uma grande metrópole nacional, duas metrópoles nacionais, nove metrópoles, 11 capitais regionais A, 20 capitais regionais B e 39 capitais regionais C. No conjunto, esses centros urbanos estão assim distribuídos por macrorregião: 10 no Norte, 21 no Nordeste, 5 no Centro-Oeste, 29 no Sudeste e 17 no Sul.

Os Quadros 2 e 3, apresentam, respectivamente, o indicador habitantes por torre/antena para os 31 centros urbanos mais importantes das nove unidades federativas com maior carga informacional segundo a teledensidade e para os 51 centros urbanos das demais. Cotejando os dados de ambos os quadros, sintetizados na Figura 2, e tomando como parâmetro a média brasileira de 3.428,7 habitantes para cada torre/antena, são dotados de mais oferta de infraestrutura os 47 centros que estão abaixo da média e, de menos infraestrutura, os 35 que estão acima, pois, quanto menor o indicador maior é a quantidade de torres/antenas instaladas.

Esses resultados constituem uma aproximação no que se refere a melhor ou pior conectividade dos usuários, pois estão circunscritos à média brasileira de habitantes por torre/antena dentro dos limites municipais demarcados pelo IBGE. É provável que alguns dos centros urbanos aqui considerados de menos infraestrutura possam ser influenciados pela presença de torres/antenas localizadas em municípios vizinhos. Para identificar esses casos seria necessário um estudo complementar que abrangesse os recortes territoriais das 
microrregiões onde os centros urbanos estão inseridos, o que foge ao método adotado no presente artigo.

\begin{tabular}{|c|c|c|c|c|c|}
\hline \multicolumn{6}{|c|}{ Quadro 2: Habitantes por torre/antena dos Centros Urbanos de Unidades Federativas com Maior Teledensidade } \\
\hline Macrorregião & Unidade Federativa & Centro Urbano/Hierarquia ${ }^{1}$ & População ${ }^{2}$ & $\begin{array}{c}\mathrm{N}^{\circ} \text { de torres e } \\
\text { antenas }^{3}\end{array}$ & $\begin{array}{l}\text { Habitantes por } \\
\text { torre/antena }\end{array}$ \\
\hline Norte & Rondônia - RO & Porto Velho-CR B & 442.701 & 154 & $2.874,7$ \\
\hline \multirow{2}{*}{ Nordeste } & \multirow{2}{*}{ Rio Grande do Norte - RN } & Natal-CR A & 817.590 & 293 & $2.790,4$ \\
\hline & & Mossoró-CR C & 266.758 & 63 & $4.234,3$ \\
\hline \multirow{5}{*}{ Centro-Oeste } & Distrito Federal - DF & Brasília-MN & 2.648 .532 & 1.266 & $2.092,0$ \\
\hline & Goiás - GO & Goiânia-M & 1.333 .767 & 548 & $2.433,9$ \\
\hline & Mato Grosso - MT & Cuiabá-CR A & 561.329 & 271 & $2.071,3$ \\
\hline & \multirow{2}{*}{ Mato Grosso do Sul - MS } & Campo Grande-CR A & 805.397 & 349 & $2.307,7$ \\
\hline & & Dourados-CR C & 200.729 & 47 & $4.270,8$ \\
\hline \multirow{16}{*}{ Sudeste } & \multirow{3}{*}{ Rio de Janeiro - RJ } & Rio de Janeiro-MN & 6.390 .290 & 2.836 & $2.253,3$ \\
\hline & & Campos dos Goytacazes-CR C & 472.300 & 135 & $3.498,5$ \\
\hline & & Volta Redonda-Barra Mansa-CR C & 439.060 & 109 & $4.028,1$ \\
\hline & \multirow{13}{*}{ São Paulo - SP } & São Paulo-GMN & 11.376 .685 & 4.181 & $2.721,0$ \\
\hline & & Campinas-CR A & 1.098 .630 & 915 & $1.200,7$ \\
\hline & & Ribeirão Preto-CR B & 619.746 & 231 & $2.682,9$ \\
\hline & & São José do Rio Preto-CR B & 415.769 & 121 & $3.436,1$ \\
\hline & & Araçatuba-CR C & 183.441 & 60 & $3.057,4$ \\
\hline & & Araraquara-CR C & 212.617 & 68 & $3.126,7$ \\
\hline & & Bauru-CR C & 348.146 & 124 & $2.807,6$ \\
\hline & & Marília-CR C & 219.664 & 58 & $3.787,3$ \\
\hline & & Piracicaba-CR C & 369.919 & 120 & $3.082,7$ \\
\hline & & Presidente Prudente-CR C & 210.393 & 63 & $3.339,6$ \\
\hline & & Santos-CR C & 422.569 & 219 & $1.929,5$ \\
\hline & & São José dos Campos-CR C & 643.603 & 222 & $2.899,1$ \\
\hline & & Sorocaba-CR C & 600.692 & 187 & $3.212,3$ \\
\hline \multirow{7}{*}{ Sul } & \multirow{7}{*}{ Rio Grande do Sul - RS } & Porto Alegre-M & 1.416 .714 & 700 & $2.023,9$ \\
\hline & & Caxias do Sul-CR B & 446.911 & 166 & $2.692,2$ \\
\hline & & Passo Fundo-CR B & 187.298 & 63 & $2.973,0$ \\
\hline & & Santa Maria-CR B & 263.662 & 77 & $3.424,2$ \\
\hline & & Ijuí-CR C & 79.396 & 20 & $3.969,8$ \\
\hline & & Novo Hamburgo/São Leopoldo-CR C & 456.544 & 140 & $3.261,0$ \\
\hline & & Pelotas-Rio Grande-CR C & 528.277 & 172 & $3.071,4$ \\
\hline \multicolumn{3}{|c|}{ Total Centros Urbanos } & 34.479 .129 & 13.978 & \\
\hline \multicolumn{3}{|c|}{ Total Brasil / Média } & 193.946 .886 & 56.577 & $3.428,7$ \\
\hline
\end{tabular}

Fontes: 1-Regic/IBGE, 2007 (GMN-Grande Metrópole Nacional, MN-Metrópole Nacional, M-Metrópole, CRA, B e C-Capital Regional); 2-IBGE, Estimativa da População, 2012; 3-Anatel(b), 2012(b); 


\begin{tabular}{|c|c|c|c|c|c|}
\hline Macrorregião & Unidade Federativa & Centro UrbanolHierarquia' & Populaçãox & $\begin{array}{c}\text { N' de } \\
\text { Torres e } \\
\text { Antenas" }\end{array}$ & $\begin{array}{r}\text { Habitantes por } \\
\text { TorrelAntena }\end{array}$ \\
\hline \multirow{6}{*}{ Norte } & Acre - AC & Rio Branco-CRC & 348.354 & 100 & $3.483,5$ \\
\hline & Amapá - AP & Macapá-CRC & 415.554 & 99 & $4.197,5$ \\
\hline & Amazonas - AM & Manaus-M & 1.861 .838 & 573 & $3.249,3$ \\
\hline & Pará - PA & $\begin{array}{l}\text { Belém-M } \\
\text { Marabá-CRC } \\
\text { Santarém-CRC }\end{array}$ & $\begin{array}{r}1.410 .430 \\
243.583 \\
299.419\end{array}$ & $\begin{array}{r}460 \\
58 \\
50\end{array}$ & $\begin{array}{l}3.066,2 \\
4.199,7 \\
5.988,4\end{array}$ \\
\hline & Roraima - RR & Boa Vista-CRC & 296.959 & 68 & $4.367,0$ \\
\hline & Tocantins - TO & $\begin{array}{l}\text { Palmas-CRB } \\
\text { Araguaína-CRC }\end{array}$ & $\begin{array}{r}242.070 \\
156.123\end{array}$ & $\begin{array}{r}107 \\
37\end{array}$ & \begin{tabular}{r|}
$2.262,3$ \\
$4.219,5$
\end{tabular} \\
\hline \multirow{8}{*}{ Nordeste } & Alagoas - AL & $\begin{array}{l}\text { Maceió-CRA } \\
\text { Arapiraca-CRC }\end{array}$ & \begin{tabular}{r|}
953.393 \\
218.140
\end{tabular} & $\begin{array}{r}324 \\
40\end{array}$ & $\begin{array}{l}2.942,6 \\
5.453,5\end{array}$ \\
\hline & Bahia - BA & $\begin{array}{l}\text { Salvador-M } \\
\text { Feira de Santana-CRB } \\
\text { Ilhéus-CRB } \\
\text { Vitória da Conquista-CRB } \\
\text { Barreiras-CRC }\end{array}$ & $\begin{array}{r}2.710 .968 \\
568.099 \\
189.052 \\
315.884 \\
141.081 \\
\end{array}$ & \begin{tabular}{r|}
742 \\
107 \\
51 \\
45 \\
28 \\
\end{tabular} & $\begin{array}{l}3.653,6 \\
5.309,3 \\
3.706,9 \\
7.019,6 \\
5.038,6\end{array}$ \\
\hline & Ceará - CE & $\begin{array}{l}\text { Fortaleza-M } \\
\text { Juazeiro do Norte-Crato-Barbalha-CRC } \\
\text { Sobral-CRC }\end{array}$ & $\begin{array}{r}2.500 .194 \\
436.187 \\
193.134 \\
\end{array}$ & \begin{tabular}{r|}
718 \\
80 \\
26 \\
\end{tabular} & $\begin{array}{l}3.482,2 \\
5.452,3 \\
7.428,2\end{array}$ \\
\hline & Maranhão - MA & $\begin{array}{l}\text { São Luis-CRA } \\
\text { Imperatriz-CRC }\end{array}$ & $\begin{array}{r}1.039 .610 \\
250.063\end{array}$ & $\begin{array}{r}302 \\
52 \\
\end{array}$ & $\begin{array}{l}3.442,4 \\
4.808,9 \\
\end{array}$ \\
\hline & Paraíba - PB & $\begin{array}{l}\text { João Pessoa-CRA } \\
\text { CampinaGrande-CRB }\end{array}$ & $\begin{array}{l}742.478 \\
389.995\end{array}$ & $\begin{array}{r}266 \\
84\end{array}$ & $\begin{array}{l}2.791,3 \\
4.642,8 \\
\end{array}$ \\
\hline & Pernambuco - PE & $\begin{array}{l}\text { Recife-M } \\
\text { Caruaru-CRC } \\
\text { Petrolina-Juazeiro-CRC }\end{array}$ & $\begin{array}{r}1.555 .039 \\
324.095 \\
506.851\end{array}$ & $\begin{array}{r}589 \\
80 \\
89\end{array}$ & $\begin{array}{l}2.640,1 \\
4.051,2 \\
5.695,0\end{array}$ \\
\hline & Piauí - PI & Teresina-CRA & 830.231 & 227 & 3.657 .4 \\
\hline & Sergipe - SE & Aracaju-CRA & 587.701 & 193 & $3.045,1$ \\
\hline \multirow[b]{2}{*}{ Sudeste } & Espírito Santo - ES & $\begin{array}{l}\text { Vitória-CRA } \\
\text { Cachoeiro de Itapemirim-CRC }\end{array}$ & $\begin{array}{l}333.162 \\
192.156\end{array}$ & $\begin{array}{r}188 \\
53\end{array}$ & $\begin{array}{r}1.772,1 \\
3.625,6 \\
\end{array}$ \\
\hline & Minas Gerais - MG & $\begin{array}{l}\text { Belo Horizonte-M } \\
\text { Juiz de Fora-CRB } \\
\text { Montes Claros-CRB } \\
\text { Uberlândia-CRB } \\
\text { Divinópolis-CRC } \\
\text { Governador Valadares-CRC } \\
\text { Ipatinga-Cel Fabriciano-Timóteo-CRC } \\
\text { Pouso Alegre-CRC } \\
\text { Teófilo Dtoni-CRC } \\
\text { Uberaba-CRC } \\
\text { Varginha-CRC } \\
\end{array}$ & $\begin{array}{r}2.395 .785 \\
525.225 \\
370.216 \\
619.536 \\
217.404 \\
266.190 \\
430.896 \\
134.215 \\
135.549 \\
302.623 \\
125.208 \\
\end{array}$ & \begin{tabular}{r|}
1.021 \\
191 \\
78 \\
276 \\
92 \\
62 \\
115 \\
42 \\
28 \\
163 \\
44 \\
\end{tabular} & $\begin{array}{l}2.346,5 \\
2.749,9 \\
4.746,4 \\
2.244,7 \\
2.363,1 \\
4.293,4 \\
3.746,9 \\
3.195,6 \\
4.841,0 \\
1.856,6 \\
2.845,6 \\
\end{array}$ \\
\hline \multirow{2}{*}{ Sul } & Paraná - PR & $\begin{array}{l}\text { Curitiba-M } \\
\text { Cascavel-CRB } \\
\text { Londrina-CRB } \\
\text { Maringá-CRB } \\
\text { PontaGrossa-CRC } \\
\end{array}$ & $\begin{array}{r}1.776 .761 \\
292.372 \\
515.707 \\
367.410 \\
317.339 \\
\end{array}$ & \begin{tabular}{r|}
785 \\
88 \\
227 \\
112 \\
103 \\
\end{tabular} & $\begin{array}{l}2.263,4 \\
3.322,4 \\
2.271,8 \\
3.280,4 \\
3.081,0 \\
\end{array}$ \\
\hline & Santa Catarina - SC & $\begin{array}{l}\text { Florianópolis-CRA } \\
\text { Blumenau-CRB } \\
\text { Chapecó-CRB } \\
\text { Joinville-CRB } \\
\text { Criciúma-CRC }\end{array}$ & \begin{tabular}{r|}
433.158 \\
316.139 \\
189.052 \\
526.338 \\
195.614 \\
\end{tabular} & \begin{tabular}{r|}
346 \\
134 \\
43 \\
156 \\
51
\end{tabular} & \begin{tabular}{r|}
$1.251,9$ \\
$2.359,2$ \\
$4.396,6$ \\
$3.374,0$ \\
$3.835,6$
\end{tabular} \\
\hline \multicolumn{3}{|c|}{ Total Centros Urbanos } & 30.704 .580 & 9.794 & \\
\hline \multicolumn{3}{|c|}{ Total Brasil I Média } & 193.946 .886 & 56.577 & 3.428 .70 \\
\hline
\end{tabular}

Fonte: 1-Regic/BGE, 2007 (M-Metrópole, CR A, B e C-Capital Regional); 2-IBGE, Estimativa da População, 2012; 3-Anatel (b), 2012 
Figura 2: Carga Informacional dos Centros Urbanos segundo a Infraestrutura de Torres/Antenas

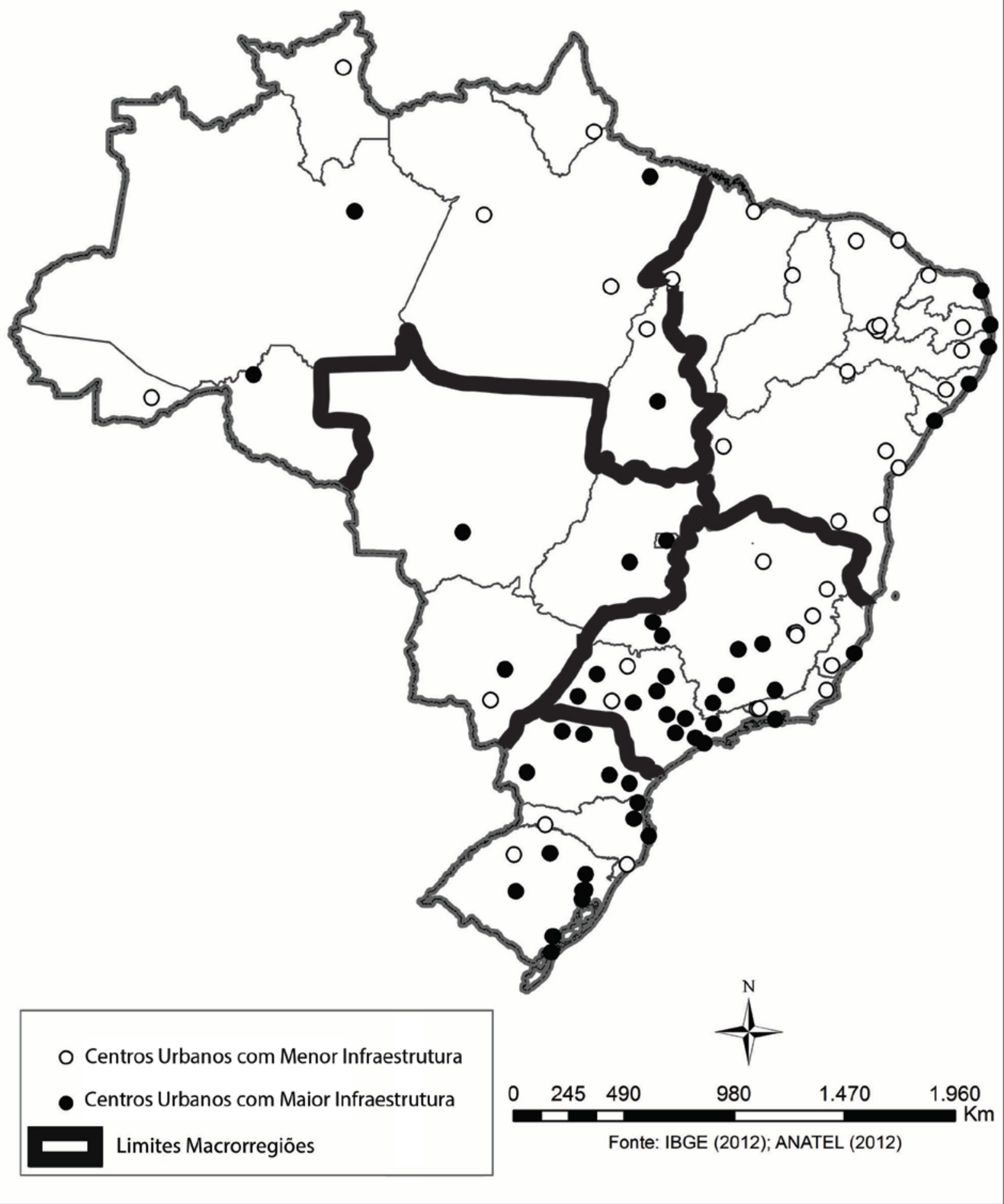

Levando em conta a alta hierarquia desses 82 centros urbanos, tais números situam-se aquém das expectativas, o que, em parte, pode ser explicado pelos indicadores do Nordeste, a

Revista Eletrônica: Tempo - Técnica - Território, V.6, N.1 (2015), 73:97 ISSN: 2177-4366 
macrorregião que conta a menor infraestrutura implantada. Seus centros mais bem aparelhados em termos de habitantes atendidos por cada torre/antena são capitais de unidades federativas - Natal, Maceió, João Pessoa, Recife e Aracaju. O mesmo acontece com a macrorregião Norte - Porto Velho, Manaus, Belém, Palmas. De fato, há um predomínio de centros mais bem aparelhados nas macrorregiões Sudeste e Sul onde estão 34 dos 47 assim classificados.

Nos dois quadros, observa-se que a hierarquia dos centros não é determinante para a infraestrutura implantada, porque exceto a grande metrópole nacional de São Paulo e as duas metrópoles nacionais de Brasília e Rio de Janeiro, em todos os demais grupos há centros com oferta de infraestrutura menor que a média. São os casos das metrópoles de Salvador e Fortaleza, das capitais regionais A de São Luís e Teresina, de sete capitais regionais B e 21 capitais regionais $C$. É digno de atenção o fato de a capital regional A de Campinas ter o melhor indicador de habitantes por torre/antena do país, seguido por Florianópolis, Vitória e Uberaba.

Por fim, cumpre ressaltar que os dados mostram uma não correspondência entre a teledensidade das unidades federativas e a oferta de infraestrutura de seus centros urbanos hierarquicamente mais importantes. O caso do Paraná, unidade federativa com baixa teledensidade, desponta como o mais ilustrativo dessa falta de correspondência porque todos seus centros possuem uma elevada infraestrutura - Curitiba, Cascavel, Londrina, Maringá e Ponta Grossa.

Embora os casos expostos possuam especificidades, relativas ao número de centros urbanos incluídos nas diversas unidades federativas, permitem observar o gap entre os indicadores de demanda per capita (teledensidade) e oferta de infraestrutura (habitantes por torre/antena). Retratam que a carga informacional contida na distribuição espacial dos objetos da trilogia celular-torre-antena, uma das formas de expressão da territorialidade informacional, deve ser medida por ambos os indicadores. Juntos, eles podem revelar as prioridades da política de atuação dos agentes sociais.

Diante da popularização do celular, admite-se que ele possa contribuir para diminuir esse gap e, portanto, reduzir as conhecidas desigualdades aqui reiteradas na identificação da carga informacional das unidades federativas e dos seus centros urbanos mais importantes. Em vários desses, além de já existir uma demanda reprimida, é grande a probabilidade de ocorrer uma demanda potencial crescente. $O$ atendimento a essas demandas vai requerer uma ação mais ativa dos agentes sociais envolvidos nas decisões de localização e regulação dos 
objetos da trilogia celular-torre-antena, outra forma de expressão da territorialidade informacional.

\section{3 - A territorialidade informacional expressa na ação dos agentes sociais}

A importância do celular para o consumidor é inequívoca, pois a ampliação da sua mobilidade traz inúmeros benefícios tanto no mundo do trabalho como na vida cotidiana. De fato, apesar de o agente fundamental do sistema de telefonia celular ser o consumidor, a ação de adquirir um aparelho celular, está inserida em uma cadeia de produção que envolve outros agentes sociais: a operadora e o Estado. São eles os responsáveis por tomar decisões sobre a localização e a regulação de dois dos objetos da trilogia, as torres e as antenas, sem as quais o consumidor não poderia utilizar adequadamente o celular adquirido.

A ação desses agentes ganha relevância na discussão de territorialidade informacional porque eles exercem o poder de controlar o uso de determinados territórios, seja alterando usos pré-existentes ou criando novos. Entretanto, esse exercício provoca a reação do proprietário e do morador que se sentem incomodados com tais decisões devido à geração de diversos impactos. Assim, não só a ação da operadora e do Estado, mas também a reação provocada expressam uma territorialidade informacional que resulta de um longo processo de negociações e conflitos.

O relato desse processo, realizado com base em uma pesquisa de natureza exploratória, parte de informações obtidas em entrevistas concedidas por técnicos de telefonia celular. Tal relato evidencia duas singularidades: a estreita ligação entre a operadora e o Estado, e entre as decisões de localização e regulamentação. A despeito de a operadora ser responsável pela localização das torres e antenas, e ao Estado competir a sua regulação, em vários momentos sua ação se entrelaça, conforme será visto a seguir.

A ação da operadora sobre a localização de torres e antenas começa com a escolha do sítio e do tipo de torre que levam em conta a demanda, a área de cobertura desejada e as características do ambiente natural e construído, a exemplo do relevo, da vegetação, da densidade e do predomínio da horizontalização ou verticalização. A demanda é determinante para definir a quantidade de torres e antenas a ser ofertada a fim de garantir uma boa qualidade de serviço. Todavia, são as características do ambiente que definem sua localização precisa, pois as antenas apóiam-se em torres de três modelos assentados diretamente no solo ou no topo de prédios:

Revista Eletrônica: Tempo - Técnica - Território, V.6, N.1 (2015), 73:97 ISSN: 2177-4366 
- Torre compacta de metal - ocupa uma área proporcionalmente pequena em relação a sua altura de 20 a 30 metros e pode ser instalada em ambientes urbanos densos para atingir um grande número de usuários (Foto 1).

- Torre de metal em treliça - ocupa uma área proporcionalmente maior em relação a sua altura de 30 metros e pode ser instalada em ambientes urbanos menos densos, zonas rurais ou próximas a rodovias para atingir um reduzido número de usuários (Foto 2).

- Treliça de metal roof top - instalada no topo de prédios dos centros urbanos onde há elevada demanda e pouca área disponível para assentar os modelos anteriores (Foto 3).

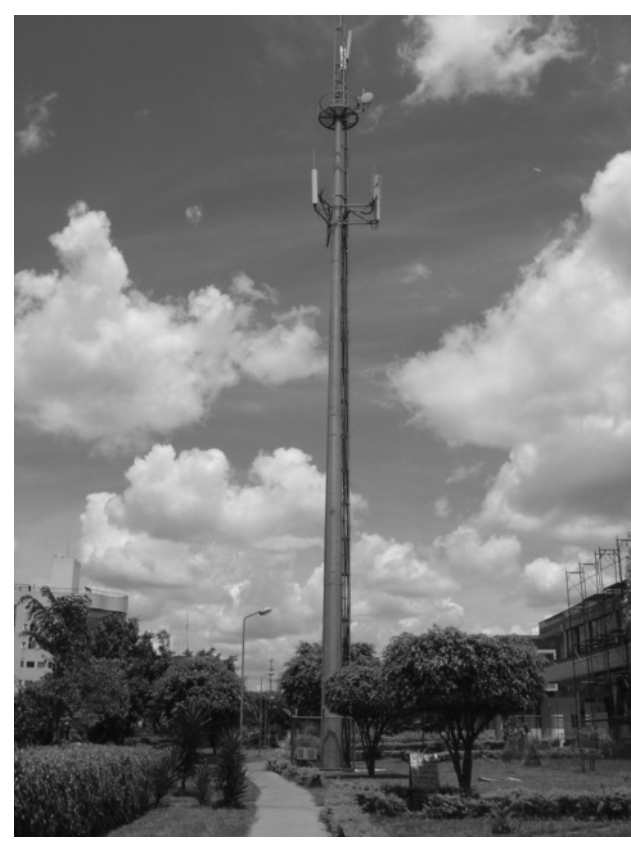

Foto 1 - Torre compacta de metal Fonte: Tofeti,2013.

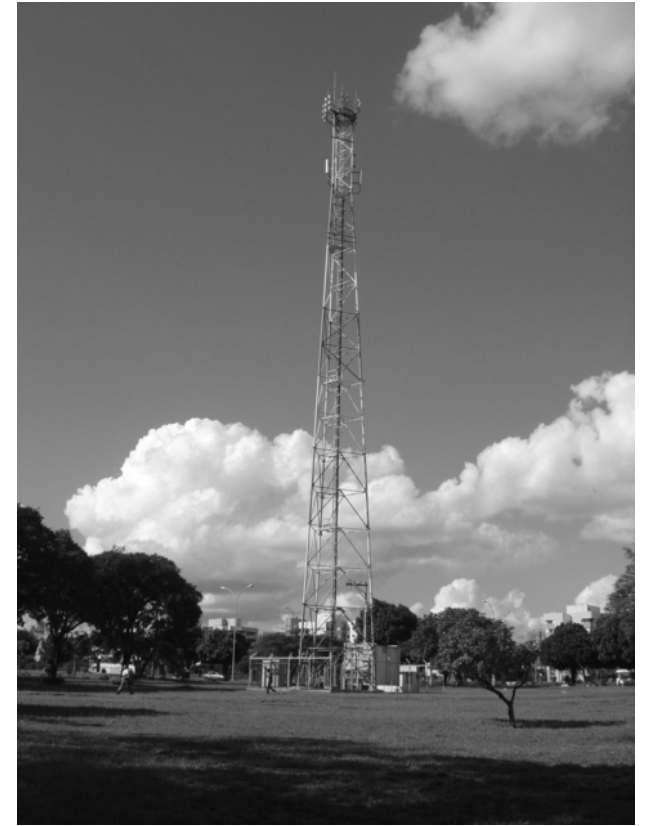

Foto 2 - Torre de metal em treliça

Fonte: Tofeti, 2013.

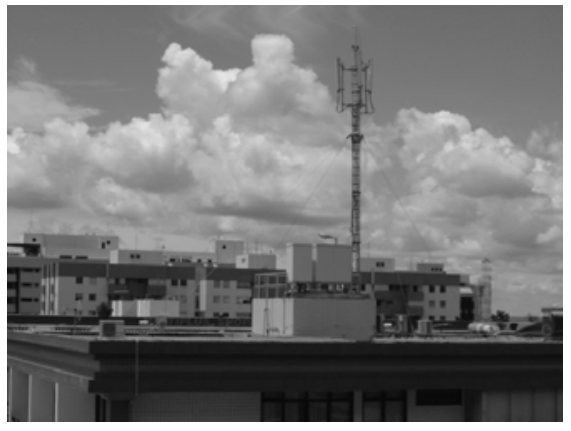

Foto 3 - Treliça de metal roof top

Revista Eletrônica: Tempo - Técnica - Território, V.6, N.1 (2015), 73:97 ISSN: 2177-4366 
Fonte: Tofeti, 2013.

Os dois primeiros modelos de torres, dado o seu porte, têm um marcante impacto na paisagem, ao passo que o terceiro confunde-se ao skyline urbano. Em quase todos os centros urbanos há uma preocupação de reduzir o número de torres para evitar a poluição visual, principalmente nas tombadas, como Brasília e cidades históricas. Os avanços tecnológicos vêm permitindo esconder as torres, isto é, dotá-las de perfis menos visíveis.

Uma vez escolhido o sítio e o modelo de torre, bem como a antena a ela associada, a operadora elabora o projeto e inicia o seu entrelaçamento com a ação reguladora do Estado nas esferas local e nacional, porque a instalação de ambos os objetos depende: do domínio particular ou público do imóvel, da localização em área urbana ou rural, da obtenção do alvará de construção, da licença sobre a radiofreqüência e do atestado de emissões eletromagnéticas. Por fim, pode depender de um estudo de impacto ambiental e de uma declaração de que não interfere em um patrimônio protegido. Portanto, a instalação fica condicionada à expedição de pelo menos cinco documentos fornecidos pelo Estado.

Quando a escolha recai em imóvel público urbano, as tratativas são efetuadas com a Prefeitura Municipal que cobra o Imposto Predial e Territorial Urbano (IPTU) pelo uso. Quando em imóvel particular urbano, a operadora negocia diretamente com o proprietário o pagamento de um aluguel, mas a Prefeitura deve emitir o alvará de construção. Em imóveis rurais, os interlocutores são o Instituto Nacional de Colonização e Reforma Agrária (INCRA), que cobra o Imposto Territorial Rural (ITR), ou o proprietário. Em todos os casos, a Anatel sempre está presente e, em alguns, são consultados órgãos federais ou estaduais que cuidam do meio ambiente e o Instituto do Patrimônio Histórico e Artístico Nacional (IPHAN).

Tais procedimentos revelam que a ação da operadora, em tese, ocorre sob um tênue equilíbrio de forças com o Estado de modo a implantar uma rede de torres e antenas de acordo com os padrões da Anatel e conciliar as regras de uso do território. É comum a operadora receber negativas ante as exigências cada vez mais criteriosas das prefeituras e da vizinhança o que leva a buscar sítios alternativos. A título de exemplo, a

Revista Eletrônica: Tempo - Técnica - Território, V.6, N.1 (2015), 73:97 ISSN: 2177-4366 
Prefeitura de Belo Horizonte instituiu as seguintes normas de localização para torres e antenas: distância mínima de 100 metros entre as edificações e as torres das Fotos 1 e 2 e de 30 metros em relação ao modelo roof top. Outras prefeituras definiram distâncias mínimas a serem respeitadas no que tange às escolas e aos hospitais.

O endurecimento das regras de uso do território é a principal queixa da operadora, uma vez que a demanda oriunda da telefonia celular das gerações $3 G$ e $4 G$ requer um aumento na quantidade de torres e antenas. Em 2012, a Anatel puniu as operadoras que atuavam no mercado brasileiro em virtude da má qualidade do serviço prestado. Foram proibidas de assinar novos contratos com consumidores enquanto não apresentassem planos de investimento na infraestrutura do sistema de telefonia celular. Essa proibição, segundo a Revista Carta Capital (2013), gerou previsões de investir 25 bilhões de reais/ano até 2017. A dizer por esses argumentos, parece que o Estado age de modo antagônico nas esferas local e nacional. Se por um lado, as prefeituras limitam a instalação indiscriminada de torres e antenas no território dos centros urbanos, a Anatel exige investimentos para melhorar a qualidade do serviço, o que pressupõe mais torres e antenas. Diante desse impasse, algumas vezes, a operadora chega a participar de fóruns municipais para compreender as regras de uso do território.

Mas as negociações e os conflitos não param por aí. Uma vez concluída a instalação da torre e da antena, a territorialidade informacional que expressa a ação da operadora e do Estado, também se expressa na reação do proprietário e do morador ante as alterações no uso do território. Alterações que passam pelos impactos relativos ao receio de problemas de saúde oriundos da radiação emanada pelas antenas, à poluição visual decorrente da modificação da paisagem e à desvalorização imobiliária.

Os técnicos entrevistados, dada a experiência de atuação em vários centros urbanos, informam que há quatro casos representativos dessa reação por serem recorrentes principalmente nas metrópoles definidas pelo IBGE-Regic:

- Proprietário-morador de imóvel urbano residencial, comercial ou de terreno onde há uma torre e antena instalada, cuja localização foi considerada estratégica pela operadora. Recebe um elevado aluguel mensal pela cessão de uso de parte do imóvel, o que possibilita valorizá-lo por meio de melhorias, razão pela qual é favorável à presença de 
tais objetos, independente dos prováveis efeitos sobre a saúde e a paisagem. Pelo fato de ser simultaneamente proprietário e morador têm o poder total de decisão. Em média, o valor do aluguel pago ao proprietário de um imóvel situado na área central e adjacências das metrópoles é de 10 Salários Mínimos (SM). Esse valor diminui progressivamente em direção as áreas periféricas chegando até a 1 (um) SM.

- Proprietário e morador de imóvel residencial ou comercial coletivo onde há uma torre e antena instalada podem divergir sobre a presença desses objetos porque nenhum dos dois tem o poder total de decisão. O proprietário recebe um aluguel alto, mas não acha que o retorno financeiro é compensatório para investir em benfeitorias significativas. Por outro lado, o morador se divide entre os que são a favor ou contra a permanência da torre e da antena. Os favoráveis argumentam que se o proprietário transferir o valor do aluguel para o condomínio as taxas podem diminuir, enquanto os contrários reforçam a preocupação com a saúde e a paisagem, embora possam usufruir de benefícios monetários. Em quaisquer desses casos há um conflito efetivo ou latente a ser negociado. - Proprietário de imóvel residencial ou comercial onde não há nenhuma torre e antena instalada, mas essa se localiza em um imóvel vizinho. É contra a sua permanência pelos iminentes efeitos nocivos à saúde e por ferir a estética da paisagem. Afirma que o valor do imóvel não diminuiu, porém pode haver mais dificuldade de vendê-lo ou alugá-lo em decorrência da presença incômoda desses objetos. Reivindica junto a operadora a retirada da torre e da antena. Segundo relatos dos técnicos, essa situação gera a maior parte das reclamações, denotando que os conflitos entre proprietários vizinhos ocorrem pelo fato de uns receberem benefícios financeiros e outros não.

- Morador que se viu surpreendido pela instalação de torres e antenas depois de ter escolhido residir em um imóvel que não tivesse esse tipo de objeto, nem mesmo nas suas proximidades, porque os consideram profundamente prejudiciais à saúde. Entra em conflito com o proprietário do imóvel onde reside e de imóveis vizinhos pela decisão ter sido tomada à sua revelia. Por vezes, organiza atos coletivos para reivindicar a retirada da torre e antena, pois, geralmente, a operadora não o consulta, motivo pelo qual enfrenta reações investidas do poder de uma Associação de Moradores.

Revista Eletrônica: Tempo - Técnica - Território, V.6, N.1 (2015), 73:97 ISSN: 2177-4366 
Os quatro casos apresentados ilustram que a localização de torres e antenas gera conflitos e traz a necessidade de negociações. Ilustram também que os comportamentos do proprietário e do morador variam de acordo com o processo de valorização imobiliária, decrescente da área central para a periferia, e de valorização da paisagem em que ocorre o inverso. $\mathrm{Na}$ área central, onde é maior a verticalização, as torres têm menor porte e são aderentes ao skyline, enquanto conforme se avança para a periferia as torres ganham realce dado o predomínio da horizontalização. Além disso, independente de localizadas mais próximas ou mais distantes da área central ou da periferia, as torres e antenas podem ter impactos ligados à saúde.

\section{Comentários finais}

O celular tornou-se um símbolo do consumo popular desde o início dos anos 2000, embora seja tão somente um dos componentes de uma trilogia de objetos geográficos que é pouco percebida: celular-torre-antena. Nasceu no âmbito do período técnicocientífico-informacional quando surgiram os debates sobre desterritorialização. No presente artigo, defende-se a ideia de que o território é essencial para o sistema de telefonia celular, pois as torres e antenas que dão suporte ao bom funcionamento do aparelho celular representam a sua âncora territorial. Mais do que reiterar a imprescindibilidade do território, reconhece-se a existência de uma territorialidade informacional que se expressa na distribuição espacial dos objetos da trilogia celulartorre-antena e na ação de agentes sociais responsáveis pela sua localização e regulação. A distribuição espacial desses objetos nas unidades federativas e nos centros urbanos hierarquicamente mais importantes, medida pelos indicadores de teledensidade e de habitantes por torre/antena, permite constatar que o Nordeste é a macrorregião que possui a menor carga informacional do Brasil. Por outro lado, a ação da operadora e do Estado, traz à tona conflitos e negociações provocadas pela reação do proprietário e do morador ante os impactos gerados na saúde, na paisagem e na desvalorização imobiliária. Especificamente, na esfera do Estado, destaca-se a atuação mais criteriosa das prefeituras municipais, cada vez mais atentas a esses impactos.

Revista Eletrônica: Tempo - Técnica - Território, V.6, N.1 (2015), 73:97 ISSN: 2177-4366 


\section{Referencial Bibliográfico}

ANATEL, 2012 (a). Disponível em<http://www.anatel.gov.br/Portal/exibirPortallnternet.do>, acesso em julho de 2013.

ANATEL, 2012 (b). Disponível em: < http://sistemas.anatel.gov.br/stel/consultas/Lista

EstacoesLocalidade/tela.asp?pNumServico=010>, acesso em julho de 2013.

CAMPOS, N. \& KRAHL, M. F. Territorialidade: Elo de ligação entre o espaço rural e o espaço urbano - algumas reflexões teórico-conceituais. In: Marília Steinberger (org.). Território, ambiente e políticas públicas espaciais. Brasília: Paralelo 15 e LGE, 2006, p. 83-100.

DODD, Annabel Z. O guia essencial para telecomunicações. Rio de Janeiro: Ed. Campus, 2000, p. 344-365.

HAESBAERT, R. Concepções de território para entender a desterritorialização. In: Território, territórios: Ensaios sobre ordenamento territorial. $2^{\mathrm{a}}$ ed. Rio de Janeiro: DP\&A, 2006, p. 43-70.

HARVEY, D. Condição pós-moderna. São Paulo: Edições Loyola, 1993.

IBGE. Contas Nacionais. Rio de Janeiro, 2011. Disponível em: < http://www.ibge.gov.br/ home/estatistica/economia/contasregionais/2011/contasregionais2011.pdf>, acesso em agosto de 2013.

IBGE. Estimativa de população brasileira 2012. Disponível em: <http://www.ibge.gov.br/home/ estatistica/populacao/Estimativa2012.shtm>, acesso em agosto de 2013.

IBGE. Região de Influência das Cidades (Regic). Rio de Janeiro, 2007. Disponível em: $<$ http://www.ibge.gov.br/home/geociencias/geografia/regic.shtm?c=6>, acesso em agosto de 2013.

LÉVY, P. Cibercultura. São Paulo: Ed. 34, 1999.

Revista Carta Capital. Ano XVIII, $\mathrm{n}^{\circ}$ 748, de 15 de maio de 2013. Relatórios Especiais Telecomunicações, p. 49.

SACK, D. R. Territorialidade Humana: sua teoria e história. Cambridge University Press, 1986.

SANTOS, M. Técnica, espaço, tempo: Globalização e meio técnico-científico informacional. $2^{\mathrm{a}}$ edição. São Paulo: Hucitec, 1996.

Revista Eletrônica: Tempo - Técnica - Território, V.6, N.1 (2015), 73:97 ISSN: 2177-4366 
A natureza do espaço. Técnica e tempo. Razão e emoção. $2^{a}$ edição. São Paulo: Edusp, 2002.

SANTOS, M. \& SILVEIRA, M. L. O Brasil: Território e sociedade no início do século XXI. 6ª Ed. São Paulo: Record, 2001.

SOUZA, M. J. L. O território: Sobre espaço e poder, autonomia e desenvolvimento. In: Iná Elias Castro, Paulo Cesar Costa Gomes e Roberto Lobato Corrêa. Geografia: Conceitos e temas. Rio de Janeiro: Bertrand Brasil, 1995, p. 77-116.

SOUZA SANTOS, B.. A territorialização/desterritorialização da exclusão/inclusão social no processo de construção de uma cultura emancipatória. São Paulo, Seminário: "Estudos territoriais de desigualdades sociais", 16 e 17 de maio de 2001, PUC/SP.

STALLING, W. Wireless communication and network. New Jersey: Ed. Prentice Hall PTR, 2002. p. 284-291

VIRILIO, P. A arte do motor. São Paulo: Estação Liberdade, 1993.

Revista Eletrônica: Tempo - Técnica - Território, V.6, N.1 (2015), 73:97 ISSN: 2177-4366 